\title{
İşletmelerde Yenilik Yönetimi ve Araştırma Geliştirme- Pazarlama-Üretim Entegrasyonunda Bilgiye Dayalı Yenilik Yaklaşımı
}

\author{
Innovation Management and Knowledge Based-Innovation Approach in \\ Research and Development-Marketing-Production Integration
}

\author{
Keti VENTURA ${ }^{1}$, Haluk SOYUER ${ }^{2}$
}

\begin{abstract}
ÖZET
Rekabetin yoğun olduğu endüstrilerde dinamik pazar yapısı, kısalan ürün yaşam eğrileri, müşteri tercih ve beklentilerinin önceden tahmin edilme zorunluluğu gibi nedenler işletmelerde sürdürülebilirliği ve bunun bir gerekliliği olan yenilik yönetimi stratejisinin varlığını ön plana çıkarmıştır. Bu kapsamda çalışmanın amacı, bu stratejiyi destekleyen iş modellerinden biri olan ve yenilik yaratma potansiyelinde etkisi en yüksek birimlerden olan araştırma-geliştirme (Ar-Ge), pazarlama ve üretim fonksiyonlarının entegrasyonunun işletmeler açısından önemini, etkileyen faktörleri ve bu süreçte işletmeler açısından bir yol haritası niteliğinde değerlendirilebilecek bilgiye dayalı yenilik yaklaşımını (Knowledge Based Innovation) ortaya koymaktır. Keşifsel bir araştırma niteliğinde tasarlanan bu çalışmada bilgiye dayalı yenilik yaklaşımının, özellikle yoğun rekabet ortamında faaliyet gösteren işletmelere yol göstermesi ve bu süreci kendi bünyelerine uyarlamalarını kolaylaştırması anlamında faydalı olacağı düşünülmektedir.
\end{abstract}

Anahtar Kelimeler: araştırma-geliştirme, pazarlama ve üretim entegrasyonu, yenilik yönetimi, sürdürülebilirlik, bilgiye dayalı yenilik

\begin{abstract}
Dynamic market structure, shortened product life cycles, urgency of predicting the preferences and expectations of customers in competition intensive industries has brought the importance of sustainability in business and the presence of innovation management strategy which is one of the necessity of it. Within this context, the aim of this paper is to explore the importance and the factors affecting the integration of research and development, marketing and production functions which are one of the functions that have the potantial of creating innovation, and also present knowledge-based innovation which can be evaluated as a guide for companies in this process. This exploratory study is tought to be beneficial for the companies especially operating in competetive environments to lead and easily adapt this process to their companies.
\end{abstract}

Keywords: research-development, marketing and production integration, innovation management, sustainability, knowledge-based innovation

\section{Gíriş}

Ulusal ve uluslararası rekabetin oldukça yoğun yaşandığı endüstrilerde, işletmeleringeleneksel olarak satış hedeflerine ulaşma amaçları artık tek başına yeterli olamamaktadır. Satış hacminin arttırılması, maliyetlerin azaltılması gibi temel hedeflerin yanında, sürdürülebilir bir karlılı̆ın sağlanması günümüzde işletmelerin en önemli hedefleri arasında yer almaktadır. Sürdürülebilirlik, müşterilerin gelecekteki istek, ihtiyaç ve beklentilerinin tahmin edilmesi ve buna yönelik olarak geliştirecekleri etkin bir yenilik stratejisi ile sağlanabilmektedir. Bu yenilik stratejisinin başarısı, işletmenin tüm fonksiyonlarının koordineli ve işbirliği içerisinde çalışması ve bunun bir kültür olarak benimsetilmesi ile mümkün olabilir. Yenilik yönetimi stratejisinin rekabetçi iş modellerini desteklediği durumlarda ancak sürdürülebilirlikten söz edilebilir. $\mathrm{Ar}-\mathrm{Ge}$, pazarlama ve üretim fonksiyonlarının yenilik yaratma sürecinde birlikte çalıştığı, müşterilerin, pazarın ve rakiplerin faaliyetlerine ilişkin veri ve enformasyonun işletmeye sürekli aktığı, depolandığı ve ilgili tüm birimlere eş zamanlı raporlandığı bilgiye dayalı yenilik yaklaşımı oldukça önemli hale gelmiştir. Çalışmanın ilk bölümünde işletmelerde yenilik kavramı ve yenilik türleri üzerinde durulmuştur. İkinci ve üçüncü bölümlerinde sırasıyla, yenilik yönetimi ve bu süreci destekleyen rekabetçi iş modelleri ile 
fonksiyonlar arası entegrasyonun önemi ayrıntılı olarak açıklanmıştır. Son bölümde de işletmelerde bu entegrasyona geçişi kolaylaştıracak bilgiye dayalı yenilik yaklaşımı değerlendirilmiştir.

\section{IŞLETMELERDE YENILIK KAVRAMI VE TÜRLERi}

İşletmelerin içinde bulundukları dinamik pazar yapısı, rekabetin yoğunluğu, sürekli değişen müşteri tercihleri, işletmelerin kendi faaliyetlerini sürdürebilmek ve hayatta kalabilmelerini sağlamak için yenilik yönetimine vermeleri gereken önemi artırmıştır. OECD ve Eurostat ortak yayını olan Oslo Manual (2005) yeniliği, ürün, süreç, pazarlama yöntemi ve örgütsel yöntemlerde gerçekleştirilen ve yeni ya da önemli bir geliştirme yapılmış uygulamalar olarak tanımlamaktadır. Oslo Manual (2005)'ın önceki yenilik tanımlarından "teknolojik ürün ve süreç" ifadesi çıkartılarak, özellikle hizmet sektöründe gerçekleştirilen ürün ve süreç yenilikleri de yenilik tanımı kapsamına dahil edilmiştir. Rapor aynı zamanda, Ar-Ge'nin, yenilik yaratma sürecinin oldukça kritik bir faktörü olduğunu ancak, birçok yenilik faaliyetinin de Ar-Ge'ye ve kalifiye çalışanlara bağlı olmadan, diğer işletmeler ve kamu araştırma kuruluşlarıyla olan işbirliğine ve bilgiyi öğrenmeye/ ortaya çıkarmaya olanak sağlayan örgüt yapılarına bağlı olduğunu vurgulamaktadır.

Yenilik literatüründe gerek yenilik tanımıyla ilgili gerekseyeniliktürleri, modelleriya da sınıflandırmaları ile ilgili çok sayıda çalışma yapılmıştır. Rowley ve diğerleri (2011), 1970'lerden günümüze kadar çeşitli yazarlar tarafından yapılmış yenilik türleri çalışmalarını analiz ederek, zaman içerisinde çok sayıda yenilik sınıflaması ortaya konduğunu, yazarların kendi yorum ve algılarına göre parametrelerin değiştiğini, eklendiğini ya da çıkartıldığını vurgulamaktadır. Yenilik türleri arasında çok sayıda aynı anlamı ifade eden farklı terminolojiler kullanılmasına rağmen, eski sınıflamaların halen kullanıldığı görülmektedir. Örneğin, Knight (1967) yeniliği örgütsel yapı, üretim süreci, insan ve ürün/hizmet şeklinde; Oke (2007), ise yeniliği ürün, hizmet ve süreç yeniliği olarak sınıflandırmaktadır.

Literatürde birçok çalışmada kullanılan OECD Oslo Manuel (2005) sınıflamasında yapılan tanımlamalara göre, "ürün yeniliği", ürünün/hizmetin özelliklerinde ya da kullanım alanlarında yapılmış "yeni" ya da "önemli bir geliştirme" olarak ifade edilmektedir. Tanımda sözü edilen önemli geliştirmeler, ürünün teknik özelliklerinde, bileşenlerinde, malzemelerinde, yazılımında ya da fonksiyonel özelliklerinde olabilmektedir. Yeni ürünler, işletmenin özellik ve kullanım alanı açısından üretmiş olduğu, diğer ürünlerden farklı olan ürün ve hizmetlerdir. Ayrıca, teknik özelliklerinde küçük değişiklikler yapılarak yeni bir kullanım alanı yaratılmıs ürünler de ürün yeniliği kapsamında değerlendirilmektedir. Hizmet yeniliği ise hizmetlerin müşteriye ulaştırılma yöntemlerinde yapılan önemli geliştirmelerdir. Bu geliştirmeler, mevcut hizmetlere yeni fonksiyonlar veya özellikler ya da tamamıyla yeni hizmetler sunulmasıyla ilişkilidir.

Üretim ya da dağıtım yönteminde "yeni" ya da "önemli bir geliştirme yapılmış" uygulamalar "süreç yeniliği" olarak tanımlanmaktadır. Bu yenilik türü, tekniklerde, kullanılan araç gereçlerde ve/ veya yazılımlarda yapılan değişiklikler ile ilgilidir. Süreç yeniliğinde amaç, birim başı üretim/dağıtım maliyetlerini düşürmek, kaliteyi arttırmak ya da yeni veya geliştirilmiş ürünler üretmektir. "Pazarlama yeniliği" ise, ürünün tasarımında/ambalajında, ürün yerleştirmesinde, tutundurulmasında ya da fiyatlandırmasında yapılan ve önemli değişimleri içeren yeni pazarlama yöntemlerinin uygulanmasıdır. Son olarak "örgütsel yenilik" ise işletmenin iş modellerinde, işletmenin iç bünyesinde ya da dış ilişkilerinde yeni örgütsel yöntemlerin kullanılmasıdır. Burada amaç, yönetsel ya da operasyon maliyetlerini azaltmak, işletmede çalışan memnuniyetini arttırmak ve malzeme maliyetlerini düşürmektir. Bu tip yenilikler, örgütsel öğrenmeyi ve işletme içi bilgi paylaşımına yönelik yeni uygulamaları, işgücü geliştirme programları gibi yenilikleri kapsamaktadır.

İşletmelerde uygulanan ve yukarıda sözü edilen yenilik türleri hangisi olursa olsun, bu yeniliklerin işletme bünyesinde sürdürülebilir olması ancak yenilik yönetiminin etkin bir şekilde gerçekleşmesine bağlı olmaktadır.

\section{IŞLETMELERDE YENILIK YÖNETIMI VE SÜRDÜRÜLEBILIIRLIK}

Günümüzde işletmelerin performansı bir bütün olarak tedarik zinciri yönetimi performansına bağlı olmaktadır. Özellikle pazar ve müşteri ihtiyaçlarının önceden tahmin edilmesi, hedef müşteri kitlesinin bugünkü siparişleri ve talepleri yanında, gelecekteki müşteri beklentilerini ve intiyaçlarını karşılayacak stratejilerin geliştirilmesi ile sürdürülebilir bir rekabet avantajından söz etmek mümkün olabilir. Bu kapsamda, yeni ürün, teknoloji ve tasarımların geliştirilmesi, tanıtımlarının yapılması, pazarlanması ve hatta işletme düzeyinde yönetimi ile sürdürülebilir bir yenilik stratejisinden bahsedilebilmektedir. Sürdürülebilirliğin başarısı için etkin bir pazarlama ve 
verimli bir üretim stratejisi çerçevesinde, işletmelerin varlıklarının, bütçelerinin ve süreçlerinin sürekli izlendiği ve değerlendirildiği bir yenilik yönetimi stratejisinin varlığı oldukça önemli hale gelmiştir (Closs, vd., 2011).Yenilik yönetimi, yeni fikir geliştirme aşamasından, pazar için ürün ya da süreç geliştirme/ uyarlama aşamasına kadar tüm yenilik sürecinin yönetilmesidir (Ojasalo, 2008).

Yenilik yönetimi birçok çalışmada çeşitli evreleri itibariyle ele alınmıştır (Rogers, 1996; Niosi, 1999; Liyanage v.d., 1999; Miller, 2001; Ortt ve Duin, 2008). Ortt ve Duin (2008) geçmişten günümüze kadar yenilik yönetiminde yer alan yenilik yaklaşımı evrelerini değerlendirerek, evreler arasındaki faklılıkları ortaya koymuştur. 1960 öncesinde, işletme stratejileri genellikle teknoloji odaklı olup, hedef, teknolojik buluşlarla yenilik yapmak ve büyüyebilmek olmuştur. Birçok işletmede Ar-Ge departmanları itici güç olan birimler olarak faaliyet göstermiştir. Bu dönemde yenilik, araştırmacıların bireysel faaliyetlerinden oluşan $\mathrm{Ar}-\mathrm{Ge}$ çalışmaları olarak görülmüştür (Hidalgo ve Albors, 2008). 1960-1970 yılları arasında işletme stratejileri genellikle finansal riskleri azaltmak amacıyla, ölçek ekonomilerini yakalamak ve çeşitlendirme yapmakla bağlantılıyken, yenilik stratejileri de teknolojik ve bilimsel ilerlemeden çok, pazarın intiyaçlarını analiz etmeye dayalı olmuştur. Bu dönemde, pazar intiyaçlarının belirlenmesi, yenilik yaratmanın itici gücü olarak görülmüş, yenilik süreçlerinin disiplinler arası ve proje bazlı yönetilme konusu önemli hale gelmiştir. 1970'ler ile 1990'ların başlarına kadar olan dönemde, işletme stratejileri, maliyetin kontrolü ve düşürülmesine yönelik olmuştur. Teknoloji bilgisi ve pazar ihtiyaçları yenilik sürecinde birlikte kullanılmış, iç ve dış iş ortaklarıyla ağ yapısı şeklinde bir iş modeli geliştirilmesi esas olmuştur. 1990'ların başından $2000^{\prime}$ li yılların başlarına kadar olan dönemde ise işletme stratejileri genellikle öz yetkinliklere dayalı gerçekleşmiştir. Bu dönemde stratejik işbirlikleri ve pazara giriş zamanlaması oldukça önemli hale gelmiştir. Gelişme hızının arttırıması için birçok iş ortağının sisteme dahil edildiği ağ yapısı ve yeni iş ortaklarını sisteme entegre eden iş modelleri söz konusu olmuştur.

Ar-Ge'ye yapılan büyük yatırımların hem maliyetleri arttırması hem de ürün yaşam dönemlerinin kısalması nedeniyle günümüzde sadece Ar-Ge faaliyetlerine yatırım yapmanın, sürdürülebilir bir yenilik yaratmak için tek başına etkili ve yeterli olmadığı görülmektedir. Bu nedenle günümüzde teknoloji ve $\mathrm{Ar}$-Ge yatırımlarının yanı sıra yeniliğin yeni iş modelleri üzerine kurulması gerekliliği ön plana çıkmıştır (Chesbrough, 2008).

Ortt ve Duin (2008) işletmelerin yenilik süreçlerini yönetirken yenilik politikalarının, işletmenin türünün, endüstrinin yapısının ve hatta ülke kültürünün dahi etkili olduğunu, diğer bir ifadeyle içsel ve dışsal birçok çevresel faktörün yenilik yönetiminde kritik bir rol oynadığını ifade etmiştir. Dolayısıyla bu durum, her işletmenin yenilik süreçlerini kendi bağlamında değerlendirmesi gerekliliğini vurgulayan durumsallık yaklaşımının önemini ortaya koymaktadır. Hidalgo ve Albors (2008) yeniliğin, her firma için en yeni teknolojiyi kullanmak olmadığını aksine, her firmanın içsel ve dışsal kaynaklarıyla yeni bir düşünme tarzı ve yaratıcı çözümler bulmak olduğunu belirtmektedir. Ayrıca, özellikle de iş zekası, müşteri ilişkileri yönetimi, proje yönetimi ve tedarik zinciri yönetimi gibi bilgi-yoğun hizmetler sunan organizasyonlar (knowledge-intense organizations) ile yapılan ortak çalışmalar neticesinde, üretilen bilginin, işletme amaç ve politikalarıyla kesiştiği noktada işletmeler için yenilikten söz edilebileceğini vurgulamaktadır.

Yenilik yönetimine ilişkin literatürde çok sayıda model (Goffin ve Pfeiffer, 1999; Goffin ve Mitchell, 2005) önerilmektedir. Drejer (2002), yenilik yönetimi faaliyetlerini,

- müşteri isteklerini karşılayacak teknoloji ile pazarları entegre eden teknik entegrasyon,

- departmanlar arası işbirliği ve çapraz fonksiyonel faaliyetlerin etkili olduğu yenilik süreci,

- teknoloji ya da yetkinlik gelişimine yönelik projelerin öngörüldüğü stratejik teknoloji planlaması,

- örgütsel değişim ile yeniliklerin geliştirildiği ya da yenilikler tarafından geliştirilen iş geliştirme süreci,

- olmak üzere dört kategoride toplamıştır.

Diğer taraftan yenilik yönetimi alanında en sık kullanılan modellerden bir diğeri ise Goffin ve Mitchell (2005)'ın Yenilik Pentatlon Yapısı (Innovation Pentathlon Framework) modelidir. Bu yapıya göre, yenilik yönetiminin beş temel alanı vardır: yenilik stratejisi yaratma, yeni fikirler oluşturma, fikirleri kendi içlerinde önceliklendirme ve seçme, seçilen fikirleri uygulama ve işletmenin tüm fonksiyonlarında çalışanları sürece dahil etme.

Modelin ilk aşaması olan yenilik yaratma stratejisi firma için belki de en önemli aşama 
olarak tanımlanmaktadır. Bu aşamada, strateji belirlenirken tüm iş ortaklarının ve özellikle müşterilerin memnuniyetinin ön planda tutulması ve mevcut ürün/hizmetlerin müşterilerin gelecekteki isteklerini karşılamada ne kadar yeterli olacağının analiz edilmesi gerekmektedir. İkinci aşamada yaratıcılığın ve bilginin yönetilmesi gerekmektedir. Özellikle takımların birlikte çalıştığı bir kültürün yaratılması oldukça önemlidir. Bu şekilde işletme bünyesinde çeşitliliğin desteklenmesi, projelerde doğru kişilerin görevlendirilmesi, işletmede tartışma ortamının yaratılması, işletmede çalışan herkesin desteğinin alınması gibi faaliyetler uygun kültürün yaratılmasında oldukça önemli bir rol oynamaktadır. Modelin önceliklendirme ve seçim aşamasında, finansal, niteliksel ve niceliksel ölçütler ile yönetsel yetkinlikler göz önünde bulundurulmalıdır. Uygulama aşamasında ise müşteri ihtiyaçları doğrultusunda, yeni fikirlerin etkin uygulanması ile proje yönetimi tekniklerinin kullanımı ve yüksek düzeyde risk ve belirsizliğin yönetilmesi gerekmektedir. Son aşama, işletme içinde bir yenilik kültürünün oluşturulması aşamasıdır. Bu aşama da özellikle çapraz fonksiyonel, yüz yüze ya da sanal takımların oluşturulması, içsel girişimciliğin özendirilmesi ve yenilik kültürünün yaratılması açısından oldukça önemlidir.

\section{YENILIK YÖNETIMINI DESTEKLEYEN REKABETÇi iş MODELLERI VE FONKSIYONLAR ARASI ENTEGRASYON}

Günümüzde küresel ekonomideki gelişmeler ile iletişim ve bilgisayar teknolojilerindeki ilerlemeler, müşteri ile tedarikçi arasındaki geleneksel dengenin değişikliğe uğramasına ve müşteri ile pazar yönelimli olarak yeniden tanımlanmasına neden olmuştur. Küresel boyut, müşterilerin farklı intiyaçlarının ve alternatiflerinin olmasını, tedarikçilerin de tedarik seçeneklerini daha şeffaf, esnek ve müşteri odaklı hale getirmelerini gerektirmektedir. Tüm bu gelişmeler, işletmelerin müşterilerine sundukları değerönerilerini yeniden gözden geçirmelerini gerekli kılmaktadır. Bu yeni çevre şartlarında müşteri ihtiyaçlarını sadece doğru tespit etmek yeterli olmamakta, sunulan yeni ürün ve hizmetlerden nasıl değer elde edilebileceğini ortaya çıkarmak önemli hale gelmektedir. İşletmelerin iyi geliştirilmiş bir iş modeli olmaksızın, geliştirdikleri yeni ürün ve hizmetlere ilişkin değer sağlamaları ya da değer elde etmeleri sürdürülebilirliği sağlamak anlamında oldukça zor olacaktır (Teece, 2010). Yeniliğin işletme bünyesinde yönetilmesi ve sürdürülebilirliğinin sağlanabilmesi için sürekli olarak pazarın ihtiyaçlarının araştııılması ve izlenmesi gerekmektedir (O'Connor ve Rice, 2001). Müşterilerin ihtiyaçları, tercihleri, beklentileri ve ürün/hizmetlerin potansiyel kullanım alanları gibi bilgilerin önceden sağlanması, hem tasarım hem teknik geliştirme hem de üretim sürecinin planlanması açısından oldukça önemli hale gelmiştir. İşletme içerisinde fonksiyonel birimler arası iletişim ve etkileşimin artması, pazar istihbaratının zamanında ve etkin oluşmasını sağlayacaktır (Tsai, 2014). Böylece zamanında elde edilen pazar istihbaratı ile pazarın ihtiyaç, beklenti ve tercihleri doğru zamanda öğrenilecek ve işletmenin fonksiyonları arasında geliştirilen sürekli işbirliği ve koordinasyon ile daha başarılı yenilikler yapılabilecek ve rekabet avantajı elde edilebilecektir.

İşletmelerde fonksiyonlar arası işbirliği, birimler arası koordinasyonun işletmeye sağlayacağı fayda göz önünde bulundurularak, tüm fonksiyonel birimlerin çeşitli hedeflerinin, öncelik sıralamasının yapılması ile mümkün olabilecektir (Olson, 2001). Fonksiyonel entegrasyon, yeni ürün geliştirme faaliyeti gibi, işletmelerin iç bünyesinde ve/veya işletmeler arası fonksiyonların bilgi paylaşımı ve fonksiyonlar arası kaynakların dağılımı konularında operasyonel birlikteliği ifade etmektedir (Song vd.,1997). Bu birliktelik çoğunlukla Ar-Ge, üretim ve pazarlama departmanlarının entegrasyonu şeklinde görülmektedir. Bu entegrasyon, bu üç işletme fonksiyonunun yeni ürün/hızmet geliştirme sürecinde birlikte çalışmasını gerektiren çeşitli faaliyetlerde harcadıkları ortak ve bütünsel çaba olarak tanımlanmaktadır (Griffin, A. ve Hauser, 1996). Sözü edilen entegrasyonun derecesi, pazar ve rekabet istihbaratının fonksiyonlar arasında oluşturulması ve yayılması esnasında gerçekleşen etkileşim düzeyi ile bilgi paylaşımı, koordinasyon ve ortak hareket etme düzeyine bağıı olmaktadır (Ruekert ve Walker, 1987).

Literatürde fonksiyonlar arası entegrasyon genel olarak kaynak bağımlılığı teorisi ve durumsallık teorisi (Song ve Xie, 2000) kapsamında incelenmiştir. Fonksiyonlar arası entegrasyon intiyacının temelinde yer alan kaynak bağımlıı̆̆ı teorisine göre, her işletme fonksiyonunun kendi bilgi ve kaynaklarının olduğunu ancak, yeni ürün geliştirme gibi departmanlar arası ortak çalışmanın gerektiği süreçlerde, söz konusu departmanların kaynaklarının diğer departmanlara bağımlı olmasını ifade etmektedir (Song ve MontoyaWeiss, 2001). Durumsallık yaklaşımı ise, yeni ürün geliştirme süreci gibi ortak çalışma alanlarında yüksek düzeyde bir fonksiyonlar arası entegrasyonun her koşulda başarılı olamayacağını, farklı koşullara (ürünün yeniliği, işletmenin özellikleri, çevre) bağlı olarak başarılı olunabileceğini ifade etmektedir 
(Sherman vd.., 2005; Song v.d.., 1998). Genellikle işletmeler, yenilik süreçlerini yönetirken çevresel belirsizliklerle mücadele edilmesinin gerekli olduğu durumlarda fonksiyonlar arası entegrasyon gibi çeşitli iş modellerini uygulayarak bu belirsizliği en aza indirmelidirler (Koufteros vd., 2002). Sözü edilen entegrasyon, işletmelerde disiplinler arası proje takımları, eğitim programları, iş rotasyonu, fiziksel tesislerin yeniden konumlandırılması ve tasarımı gibi bilgi teknolojilerine ve işbirliğine dayalı faaliyetlerle gerçekleşebilmektedir. Böyle bir entegrasyon işletme bünyesinde yaratıcı fikirlerin ortaya çıkmasına, kaynakların etkin ve verimli bir şekilde dağıtılmasına ve fonksiyonlar arasında koordinasyon problemlerinin azalmasında etkili olmaktadır (Griffin ve Hauser, 1996; Postrel, 2002).

Literatürde Ar-Ge-pazarlama, Ar-Ge-üretim ya da pazarlama-üretim entegrasyonu farklı koşullar altında değerlendirilmiş ve farklı etkilerinin olduğu ortaya konmuştur. Bu çalışmalar arasında ortak bir görüşün olmamasının en temel sebebi endüstriler arasındaki farklııklardan kaynaklanmaktadır (Eng ve Özdemir, 2014; Lu ve Yang, 2004; Brettel vd.,2011; Calantone ve Rubera, 2012). Ancak bu çalışmaların ortak noktası, fonksiyonlar arası entegrasyon gerekliliği vurgulanırken genellikle yeni ürün geliştirme süreci üzerinde çalışıımış olmasıdır. Yeni ürün geliştirme projeleri ne kadar yenilikçi olursa, fonksiyonlar arası entegrasyon gerekliliği de o kadar fazla olmaktadır.

İşletmelerde $\mathrm{Ar}$-Ge ve pazarlama fonksiyonları, pazar ihtiyaçlarını somut ürünlere dönüştüren önemli bir yapı olarak karşımıza çıkmaktadır (Fain ve Wagner, 2014). Ancak bu somut ürünlerin müşterilerin tercihlerine uygun şekilde üretilmesi ve zamanında teslim edilmesi de üretim ve dağıtım fonksiyonlarıyla gerçekleşecek güçlü işbirliği ile mümkün olacaktır. Leenders (2008), işletmelerde yeni ürün geliştirme performansında fonksiyonlar arası entegrasyonun etkisini ölçtüğü çalışmasında, yeni ürün geliştirme kaynakları ile işletmenin faaliyet alanı ve hedef kitlesinin kritik düzeyde önemli olduğunu belirtmiştir. Özellikle Ar-Geve pazarlama arayüzünün yönetiminde bazı faktörlerin (kaynak düzeyi, hedef pazar çeşitliliği, ürün grubu) yeni ürün geliştirme başarısında etkili olduğunu ifade etmiştir. Kaynakların yüksek düzeyde olduğu ve etkin kullanıldığı işletmelerde yeni ürün performansı da yüksek olmaktadır. Ayrıca yüksek düzeyde entegrasyondan, hedef pazarı çok belirli olmayan ve birçok pazar bölümünde ve ürün grubunda faaliyet gösteren işletmelerin, daha dar ve hedef pazarı belirli olan işletmelere göre daha az fayda sağlayacağını ortaya koymuştur. Özellikle Ar-
Ge ve pazarlama entegrasyonunda, yüksek düzeyde etkileşim tek başına yeterli olmamakla beraber, bu etkileşim için işbirliği kültürünün işletme içinde yaratılması gerekmektedir. Yaratılacak işbirliğinde etkileşim sıklığından ve yoğunluğundan çok (haftalık toplantı, değişim programları ve komite sayısı, yerleşimin yeniden tasarımı gibi) fonksiyonlar arası güçlü bir bağın yaratılması ve karar verme mekanizmasının tek bir merkezden yönetilmediği, katılımcı karar vermenin üst yönetim tarafından desteklendiği bir kültürün yaratılması oldukça önemlidir (Ayers vd., 2001).

Yeni ürün geliştirme sürecinin başarısında Ar-Ge ve pazarlama arasındaki çapraz fonksiyonel birimlerin entegrasyon düzeyinin etkili olduğu görülmektedir. Özellikle işletmenin formel yapısı, merkezileştirme politikası ve örgütsel iklim çapraz fonksiyonel birimlerin entegrasyon düzeyini etkilemektedir (Song ve Thieme, 2006; Fain ve Wagner, 2014) Sözü edilen bu faktörlerden formel yapı, işletmenin kural ve prosedürleri kullanma ve uygulama düzeyini; merkezileştirme, işletmenin karar verme düzeyini ve katılımcıların karar alma sürecine dahil edilme düzeyini; örgütsel kimlik ise çalışanlar tarafından işletmenin içsel doğasının (esneklik, ödül sistemi, değerler vb.) algılanma düzeyini ifade etmektedir (Fain ve Wagner, 2014).

Yukarıda sözü edilen fonksiyonlar arası entegrasyon mekanizması, işletme bünyesindeki entegrasyon düzeyini belirlemeye yardımcı olabileceği gibi, özellikle rekabetin oldukça yoğun olduğu, pazar istihbaratının günden güne daha da kritik hale geldiği endüstrilerde, pazar istek, intiyaç ve tercihlerini hızlıca tespit edebilme ve işletme bünyesinde Ar-Ge-pazarlama ve üretim fonksiyonlarının işbirliğini ve koordineli çalışması gerekliliğini de ön plana çıkarmaktadır.

\section{BILGIYE (KNOWLEDGE) DAYALI YENILIK YAKLAŞIMI VE SISTEM ENTEGRASYONU}

İsletmelerde yukarıda ayrıntılı olarak açıklanan Ar-Ge-Pazarlama-Üretim fonksiyonlarının entegrasyonuna dayalı bir Yenilik Yönetim Modelinin uygulamaya geçirilmesi oldukça zorlu bir süreçtir. Literatürde geçmişten bugüne yoğun olarak üzerinde çalışılan Ar-Ge itmeli veya pazar çekmeli veya bu iki modelin entegrasyonuna dayalı Yenilik Yönetim modelleri uygulamaya geçirilmesi anlamında yol haritası önemli oranda belli ve uygulanması göreceli olarak daha kolay modellerdir. Her ne kadar bu modellerin uygulanması işletmenin faaliyet gösterdiği endüstriye, pazar ve talep yapısına, ürün/ 
hizmet karmasına, dağıtım kanalı özelliklerine göre farklııık gösterecekse de temel yenilik yönetim strateji birçok işletme için aynı özelliklere sahip olmaktadır.

$\mathrm{Bu}$ yaklaşımlarda yenilik sürecini tetikleyici unsurlar ister doğrudan Ar-Ge faaliyetleri ister pazar beklentileri olsun, sürecin sonraki adımları aynı olmaktadır. Ürün geliştirme ve tasarım sürecini, imalat ve pazarlama/satış süreci takip etmektedir. Bugün ise geleneksel yenilik yönetimi modellerinden sistem bütünlüğünü öngören Bilgiye Dayalı Yenilik yaklaşımına geçiş olmuştur. Bilgiye dayalı yenilik yaklaşımı, firmaların içsel bilgi sermayesini oluşturan yetkinlikler ile çevrelerinden (rakip, pazar, müşteri vb.) elde ettikleri bilgilerin yenilik yaratma sürecinde kullanıldığı bir bilgi yönetim sürecidir (Saulais ve Ermine, 2012).

Geleneksel yenilik yönetimi yaklaşımlarında yenilik süreci tetikleyicileri pazar dinamikleri, müşteriler, tedarikçiler ve rakipler gibi işletmenin dış çevresinde yer alan unsurlardan ve/veya Ar-Ge, tasarım, üretim, pazarlama/satış gibi işletmenin iç çevresinde yer alan birimlerden gelen biçimsel ve açık veri ve bilgi olarak değerlendirilmektedir. Bilgiye dayalı yenilik yaklaşımında ise açık veri ve bilgi yanında işletmede var olan özellikle örtük bilginin ortaya çıkarılması ve işletmenin kurumsal hafızasında gömülü hale getirilmesi temel amaçtır (Anand, 2007).

Günümüzde tüketici beklentilerindeki sürekli değişim, ürün çeşitliliğindeki hızlı artış ve ürün yaşam döngüsündeki kısalma işletmelerin rekabette ayakta kalabilmeleri için daha kaliteli ürünleri, daha düşük maliyetle, daha esnek ve daha hızlı üretmelerini ve pazara sunmalarını gerektirmektedir. Bu durum işletmelerin özellikle Ar-Ge ve tasarım faaliyetleri üzerinde önemli bir baskı oluşturmakta, bu süreçlerde ortaya çıkacak gecikmeler ve bunun sonucu oluşan maliyet artışları işletmelerin rekabet avantajını önemli ölçüde azaltmaktadır. Şurası unutulmamalıdır ki günümüzde işletmelerin bir ürün veya hizmeti ne kadar kaliteli ve düşük maliyetli ürettiği yanında değişen müşteri beklentilerine ne kadar esnek ve hızlı cevap verebildiği rekabet gücünü belirleyen en temel faktörlerden birisidir. Bu koşullar altında işletmelerin sürdürülebilirliklerini sağlayabilmeleri Ar-Ge, Pazarlama ve Üretim fonksiyonlarının güçlü entegrasyonuna dayalı bir Yenilik Yönetim Modelinin uygulamaya alınması gerekmektedir. Bu noktada bu tip bir entegrasyonun sağlanabilmesinde kritik başarı faktörlerinin neler olduğu ve nasıl bir strateji uygulanması gerektiği cevap aranması gereken önemli sorulardır. İşletmede çok donanımlı bilgi işçilerinin istihdam edildiği ve güçlü bir teknolojik alt yapıya sahip bir Ar-Ge organizasyonun, yüksek teknolojiye sahip bir üretim ve malzeme yönetim sisteminin ve üretim personelinin ve pazar yapısı ve müşterilere ilişkin çok güçlü veri ambarlarının varlığı bu tip güçlü bir entegrasyonu garanti altına alabilir mi? Bu soruya verilecek cevap kesinlikle bu tip güçlü bir alt yapının böyle bir entegrasyon için zaten temel gereklilikler olduğu fakat hiçbir şekilde yeterli olmayacağıdır.

Bilgiye dayalı yenilik yaklaşımı, sektörel intiyaçlara uygun olarak tasarlanmış sürdürülebilir teknolojilerin geliştirilmesine ilişkin süreçleri destekler nitelikte olmalıdır (Sindakis vd., 2015).Işsletmelerin içinde yer aldığı tedarik zincirinin yapısı ve karmaşıklığı yenilik yönetiminde önemli belirleyicilerden birisidir. Örneğin müşteri beklentilerine göre ürünlerin kişiselleştirilmesinin söz konusu olduğu endüstrilerde ve pazarlarda faaliyet gösteren işletmeler için her siparişin ayrı bir geliştirme ve tasarım faaliyeti gerektirmesinin yanında, Ar-Ge ve tasarım süreçlerinde de tedarikçilerle çalışmak gerekmektedir. Ar-Ge ve tasarım faaliyetlerinde işbirliği yapılan bu tedarikçiler uzmanlık alanlarına göre diğer işletmeler olabileceği gibi, üniversiteler ve kamu kuruluşları da olabilir. Diğer taraftan rakiplerle ortak Ar-Ge ve tasarım çalışmaları da gerçekleştirilebilmektedir. Bu durumda sadece ArGe, Üretim ve Pazarlama fonksiyonlarının değil tüm tedarik zincirinin entegrasyonunu sağlayacak bir Bilgiye Dayalı Yenilik Stratejisinin oluşturulması gerekir. Sadece bu stratejinin geliştirilebilmesi yeterli olmayıp, uygulamada başarılı olması için, müşteri beklentilerine, pazara ve rakiplerin faaliyetlerine ilişkin veri ve enformasyonun işletmeye sürekli akışıyla başlayan, veri ambarlarında depolanan bu veri ve enformasyonun işletmede ilgili birimler tarafından entegre bir şekilde hızla işlenmesini sağlayan, gerekli fizibilite çalışmalarının gerçekçi bir şekilde yapılabildiği ve üst yönetimin karar verme süreçlerini destekleyen anlamlı bilgiye ve raporlara dönüştürüldüğü, ilgili her birimin aynı ortak ve doğru bilgiye her an ve farklı iletişim teknolojileri ile ulaşabildiği, verilen geliştirme ve yenilik kararlarına göre süreçte yer alan tüm birimlerin, tedarikçilerin ve gerektiğinde müşterilerin entegre olmasını ve süreci işbirliği içinde yönetmelerini sağlayan güçlü bir bilgi akış alt sisteminin varlığını gerektirir.

Bu tip bir bilgi akış alt sisteminin işletmede dışsal bilgi yanında, sadece $\mathrm{Ar}-\mathrm{Ge}$, üretim ve pazarlama fonksiyonlarında değil tüm birimlerde var olan içsel ve özellikle örtük bilgiyi toplayacak, depolayacak, işleyecek ve karar verme süreçlerini 
ve yenilik faaliyetlerini destekleyecek bilgiye ve raporlara dönüştürecek bir altyapıya ve araçlara sahip olması gerekir. Böyle bir altyapının işletmede insan kaynağının özellikle deneyim ve tecrübelerinden oluşan ve uygulamada işlerini yaparken sahip oldukları ve ürettikleri örtük bilginin kurumsal bilgiye dönüşmesinde büyük faydası vardır. Bir işletmede pazarlama/satış süreçlerinde kurumsal standart uygulamalar yanında her çalışanın sorumlu olduğu kanal ve müşterilere özel geliştirdiği bir takım iş yapış yöntemleri ve bilgiler vardır. Bu bilgilerin hemen hemen tamamı çalışanların zihinlerinde, ajandalarında, elektronik postalarında veya en iyi intimalle excel tablolarındadır. Bu bilgilerin kurumsal veri ambarlarına alınması durumunda aynı işi yapan ve hatta başka birimlerde bu bilgiden yararlanarak yeni yöntemler geliştirilmesini sağlayacak çalışanların, işletmenin yenilik süreçlerine katkısı artacaktır.

\section{SONUÇ}

Yenilik ve yenilik yönetimi çok eski kavramlar olmakla birlikte, bu kavramlara yüklenen anlamlar endüstri ve pazar yapısında yaşanan değişimlere paralel olarak sürekli değişmiştir. Örneğin, geleneksel paradigmada yenilik kavramı önceleri temel bilimlerde sağlanan ilerlemelerle desteklenen ArGe faaliyetleri olarak tanımlanırken, zamanla pazar dinamiklerinde ortaya çıkan gelişmeler sonucu müşteri beklentilerinin tetiklediği $\mathrm{Ar}-\mathrm{Ge}$ faaliyetleri olarak tanımlanmıştır. Illerleyen dönemlerde işletmelerde yenilik gerek bilimsel çalışmalar ve gerekse pazar beklentileri tarafından tetiklenen faaliyetler sonucu ürün ve teknoloji de sağlanan iyileştirmeler kapsamında değerlendirilmiştir.

Günümüzde geçerli olan yenilik ve yenilikyönetimi paradigması ise sadece ürün ve teknolojide sağlanan iyileştirmeler ile sınırlı olmayıp yöntemler, süreçler ve hizmetlerde sağlanan iyileştirmeleri de kapsamakta ve yenilik faaliyetlerinin Ar-Ge, pazarlama, üretim fonksiyonlarının entegrasyonuna dayalı stratejilerle yönetilmesini öngörmektedir. Diğer taraftan, Bilgiye Dayalı Yenilik yaklaşımı işletmelerde yenilik sürecini destekleyen bilgi akışında dışsal ve açık bilginin yanında organizasyonda içsel ve örtük bilginin ortaya çıkarılması ve kurumsal hafızada gömülü hale getirilmesi üzerine odaklanmıştır.

Yeni paradigma yeniliği, dışsal ve içsel açık bilgi ve içsel örtük bilginin etkin yönetilmesi ile ürün ve teknolojiler yanında özellikle yöntemler, süreçler ve hizmetlerde sağlanan iyileştirmeler olarak ele almakta ve işletmelerin sürdürülebilirliklerini garanti altına alabilmeleri için yenilik sürecini destekleyici etkin bilgi yönetiminin önemini vurgulamaktadır. İşletmelerde sürdürülebilirliği sağlayacak yenilik yönetimi için dışsal ve içsel bilgi akışını ve yönetimini sağlayacak bilgi akış sistemlerinin varlığı önemlidir.

$\mathrm{Bu}$ çalışmada işletmelerde sürdürülebilirliği destekleyecek yenilik yönetimi stratejisinin geliştirilebilmesi açısından işletme fonksiyonlarının entegrasyonu ile dış ve iç kaynaklardan bilgi akışııın yönetilmesinin önemi ve günümüzde geçerli Bilgiye Dayalı Yenilik yaklaşımı kavramları ele alınmıştır. Bilgiye Dayalı Yenilik yönetiminde uygulamaya ilişkin modeller ise üzerinde çalışmaya devam edilebilecek bir alan olarak görülmektedir.

\section{KAYNAKLAR}

Anand, N., Gardner, H. K., Morris T. (2007), "Knowledge-Based Innovatıon: Emergence and Embedding of New Practice Areas in Management Consulting Firms" Academy of Management Journal, 50(2): 406-428.

Ayers,D. J., Gordon G. L. ve Schoenbachler, D. D. (2001), "Integration and New Product Development Success: The Role Of Formal And Informal Controls" Journal of Applied Business Research, 17(2)

Brettel, M., Heinemann, F., Engelen, A. ve Neubauer, S. (2011), "Cross-Functional Integration of R\&D, Marketing and Manufacturing in Radical and Incremental Product Innovations and Its Effects on Project Innovativeness and Efficiency" Journal of Product Innovation Management, 28, 251-269.
Calantone, R., Rubera, G. (2012) "When Should RD\&E and Marketing Collaborate? The Moderating Role Of Exploration-Exploitation And Environmental Uncertainty" Journal of Product Innovation Management, 29(1): 144-157.

Chesbrough, H. (2007) "Business Model Innovation: It's Not Just About Technology Anymore" Strategy \& Leadership, 35(6):12-17.

Drejer, A. (2002) "Situations for Innovation Management: Towards A Contingency Model” European Journal of Innovation Management, 5(1): 4-17.

Eng, T. ve Ozdemir, S. (2014) "International R\&D Partnerships and Intrafirm R\&D-Marketing-Production Integration of Manufacturing Firms in Emerging Economies" Industrial Marketing Management, 43: 32-44 
Fain, N. ve Wagner B. (2014) "R\&D-Marketing Integration in Innovation - Does Culture Matter?" European Business Review, 26(2):169-187.

Frishammar, J. ve Hörte, S.Å. (2005) “Managing External Information in Manufacturing Firms: The Impact on Innovation Performance" Journal of Product Innovation Management, 22: 399-411.

Goffin, K. ve Pfeiffer, R. (1999) Innovation Management in $U K$ and German Manufacturing Companies, London, Anglo-German Foundation.

Goffin, K. ve Rick, M. (2005) Innovation Management: Strategy and Implementation using the Pentathlon Framework, Palgrave Macmillan

Griffin, A. ve J.R. Hauser (1996) "Integrating R\&D and Marketing: A Review and Analysis of the Literature" The Journal of Prodduct Innovation Management, 13 (May): 191-215.

Hidalgo, A. ve Albors J. (2008), "Innovation Management Techniques and Tools: A Review from Theory and Practice R\&D Management, 38(2): 113-127.

Knight, K.E. (1967) "A descriptive model of intra-firm innovation process" Journal of Business, 40(4): 478-496.

Koufteros, X., Vonderembse, M.A. ve Doll, W. J. (2002) "Integrated Product Development Practices and Competitive Capabilities: The Effects of Uncertainty, Equivocality, and Platform Strategy" Journal of Operations Management, 20: 331-355.

Leenders Mark A.A.M. ve Wierenga B. (2008) “The Effect of The Marketing-R\&D Interface on New Product Performance: The Critical Role of Resources and Scope", Intern. J. of Research in Marketing, 25: 56-68.

Liyanage, S., Greenfield, P.F. ve Don, R. (1999) "Towards a Fourth Generation R\&D Management Model-Research Networks in Knowledge Management" International Journal Management, 40(4): 478-96.

Lu, I. ve Chang, T. (2002), "A Contingency Model for Studying R\&D-Marketing, International Journal of Technology Management, 24(2-3):143-151.

Lu, L. Y. Y. Ve Yang, C. (2004) “The R\&D and Marketing Cooperation Across New Product Development Stages: An Empirical Study of Taiwan's IT Industry", Industrial Marketing Management, 33: 593-605.

Miller, W.L. (2001) "Innovation for Business Growth" Research Technology Management, 44(5): 26-41.

Niosi, J. (1999) "Fourth-generation R\&D: from Linear Models to Flexible Innovation" Journal of Business Research, 45(2): 111-7.

O’Connor, G. ve Rice, M. (2001) “Opportunity Recognition and Breakthrough Innovation in Large
Established Firms" California Management Review, 43, 95-116.

OECD-Eurostat (2005) Oslo Manual Guidelines For Collecting And Interpreting Innovation Data, 3rd Ed., http://www.oecd.org/sti/inno/2367580pdf , (17.7.2015)

Ojasalo, J. (2008) "Management of Innovation Networks: A Case Study Of Different Approaches" European Journal of Innovation Management, 11(1): 51-86.

Oke, A. (2007)"Innovation Types and Innovation Management Practices in Service Companies" International Journal of Operations \& Production Management, 27(6): $564-587$

Olson, E. M., Walker, O. C., Jr., Ruekert, R. W. ve Bonner, J. M. (2001) "Patterns of Cooperation During New Product Development Among Marketing, Operations and R\&D: Implications for Project Performance" Journal of Product Innovation Management, 18: 258-271.

Ortt, J. R. ve Duin, P.A. (2008) "The Evolution of Innovation Management Towards Contextual Innovation", European Journal of Innovation Management, Vol. 11 Iss $4522-538$.

Postrel, S. (2002) "Islands of Shared Knowledge: Specialization and Mutual Understanding in Problem Solving Teams" Organization Science, 13: 303-320.

Rogers, A. D.M. (1996) "The Challenge Of Fifth Generation R\&D” Research Technology Management, July-August: 33-41.

Rowley,J. , Baregheh A., Sambrook S. (2011) “Towards an Innovation-Type Mapping Tool", Management Decision, 49(1): 73-86.

Ruekert, R. W. ve Walker, O. C., Jr. (1987) “Marketing's Interaction with Other Functional Units: A Conceptual Framework and Empirical Evidence", Journal of Marketing, 51: 1-19.

Ruekert, R. W.,Orville C, ve Walker Jr. (1987) "Marketing's Integration with Other Functional Units: A Conceptual Framework and Empirical Evidence", Journal of Marketing, 51 (January):1-19.

Saulais, P. ve Ermine J. (2012) "Knowledge Based Innovation: An Experiment On Incremental Technical Innovation", International Conference on Organizations, Institutions and Innovation in the ICT Sector: Where do we stand? Institut-Mines Telecom, Telecom Ecole de Management, Paris

Sherman, J.D., Berkowitz, D., ve Souder, W. E. (2005) "New Product Development Performance and The Interaction of Cross-Functional Integration and Knowledge Management" Journal of Product Innovation Management, 22(5): 399-411. 
Sindakis, S., Depeige A. ve Anoyrkati E. (2015) "Customer-Centered Knowledge Management: Challenges and Implications for Knowledge-Based Innovation in The Public Transport Sector" Journal of Knowledge Management, 19(3): 559 - 578.

Song, M., Di Benedetto, A. Ve Zhao, Y. (1999) "Pioneering Advantages in Manufacturing and Service Industries: Empirical Evidence From Nine Countries", Strategic Management Journal,20: 811-36.

Song, M., Montoya-Weiss, M. ve Schmidt, J. (1997) "Antecedents and Consequences of Cross-Functional Cooperation: A Comparison of R\&D, Manufacturing, and Marketing Perspectives", Journal of Product Innovation Management, 14(1): 35-47.

Song, M. ve Montoya-Weiss, M.M. (2001) "The Effect of Perceived Technological Uncertainty on Japanese New Product Development", Acad. Manag. J. 44 (1): 61-80.

Song, M. ve Thieme, R.J. (2006) "A Cross-National Investigation of The R\&D-Marketing Interface in The
Product Innovation Process" Industrial Marketing Management, 35: 308-322.

Song, M. ve Xie, J. (2000) "Does Innovativeness Moderate The Relationship Between Cross-Functional Integration and Product Performance?” Journal of International Marketing,8(4): 61-89.

Song, X. M., Thieme, R. J., ve Xie, J. (1998) “The Impact of Cross-Functional Joint Involvement Across Product Development Stages: An Exploratory Study" Journal of Product Innovation Management, 15, 289-303.

Teece, David J. (2010) "Business Models, Business Strategy and Innovation” Long Range Planning 43: 172194.

Tsai, K. ve Hsu, T. T. (2014), "Cross-Functional Collaboration, Competitive Intensity, Knowledge Integration Mechanisms, and New Product Performance: A Mediated Moderation Model", Industrial Marketing Management, 43: 293-303. 
